\title{
The Creative Process in Digital Media
}

\author{
Keywords \\ Creative process; Digital Media; Design; Creativity; Design Process.
}

This article brings recent researches on visuality and its transformations with new technologies. The study shows the analysis of the creative trajectory of some artists that proposed to share their works, allowing for a reflection on the process and on the movements of interaction about how knowledge and artistic sensitivity allow recognizing how a work of art is developed. The research is supported by the ideas of Pierre Levy and Steven Jonhson as collaborators of technical thinking and Fayga Ostrower, who developed analyses on drawing. They are, however, expanded by Cecília Salles; along the work, analytical studies connect such concepts to the creative thinking implied in the development of a work of art. The creative trajectory of the artists analyzed allows us to reflect on the interactions made, understand the choice of the digital software and the different ways of accessing digital tools that represent a communicative way before the environment. In the present study, we have the creative process shared among the following components: the artist as a user and manipulator of the software, the knowledge of the Graphic Interface and the artistic sensitivity of handling, which allow understanding the choices emerging along the entire creative process, such as the selections of the digital software and of the tools that best suit the development. The digital media creates a new niche of knowledge and focus for the research, as it accounts for creating new fields for the human being to act and, therefore, new fields of work. The investigation of new possibilities to work with the digital media is pointed out by Flusser, who shows that human beings have a functional and investigative characteristic they use for creating new inputs for production, since the processing speed in the digital media is undoubtedly extraordinary. The interface is the point of contact between humans and the machine, it is where the relationship between human beings and the digital space occurs, generating, in this exchange, the visual and graphic environment of the digital media. It is thus a communicative space of humans and digital media, where different digital information is found making the software respond to the user needs. To understand how digital resources operate in creation, we conducted a deconstruction of the drawing artistic processes, highlighting details of the digital media added to the knowledge of the Graphic Interface of the types of software under study. The deconstruction conducted in our work allowed understanding the processes involved in creating in digital media and understanding the complexity of conducting the work. The knowledge process is a fundamental point for understanding this network, since we observe in the work completed and delivered to the public, that the actions selected indicate the unfolding of the artist's trajectory. The approaches employed in our research can expand the processes for studying the subject, in the sense that they certainly deconstruct the solely technical possibilities to highlight the understanding of a creative construction process. 